\title{
Entre o material e o simbólico: as culturas políticas de um mundo romano em transformação
}

\author{
Between the material and the symbolic: the political cultures of a \\ changing Roman World
}

DENCH, E. Empire and political cultures in the Roman World. Cambridge: Cambridge University Press, 2018. 222 p.

\section{Melissa Moreira Melo Vieira*}

Recebido em: $18 / 12 / 2020$

Aprovado em: 20/01/2020

\begin{abstract}
C omo podemos compreender a experiência local das mudanças no mundo romano? Onde devemos olhar e como começar a entender os processos envolvidos? É a partir de tais questionamentos que Emma Dench fundamenta a obra Empire and political
\end{abstract} cultures in the Roman World, publicada em 2018. O livro faz parte da coleção Key Themes in Ancient History, cujo objetivo é publicar volumes com sínteses introdutórias de tópicos básicos da História Greco-Romana em um formato acessível para estudantes e professores de História Antiga. Dench transcende este objetivo inicial ao trazer uma análise complexa das mudanças político-culturais desencadeadas pelo delineamento de um modelo imperial romano, que é conciliada com uma rica discussão historiográfica sobre as principais tendências de pesquisa sobre a "romanização" entre o final do século XIX e início do século XX.

Emma Dench é professora do Departamento de Estudos Clássicos da Harvard University e atualmente ocupa o cargo de McLean Professor of Ancient and Modern History. Dench tem como áreas de interesse de pesquisa a República romana e os primeiros séculos do Império, as discussões sobre a construção do passado romano e as questões identitárias que o englobam. Ela também publicou as obras From Barbarians to new men: Greek, Roman, and modern perceptions from peoples of the Central Apennines (1995) e Romulus' asylum (2004). Concentrando-se na dimensão política das articulações entre o

* Doutoranda em História pela École Doctorale SLTC (Université de Lorraine, França), sob orientação de Cécile BertrandDagenbach e Hervé Huntzinger. Membro do grupo de pesquisa Histoire et Cultures de l'Antiquité et du Moyen Âge. 
Estado e as comunidades locais, Dench interessa-se pela intervenção ou influência direta de representantes do Estado imperial nas comunidades locais, a apropriação de sistemas e símbolos posteriormente associados à soberania romana e, sobretudo, o processo de integração das comunidades com o poder imperial.

O capítulo 1, intitulado Toward a Roman dialect of Empire, busca compreender os modos de legitimação e reivindicação de poder e soberania do Estado romano, na medida em que este competia com diversos outros sistemas de poder preexistentes. $\mathrm{O}$ estabelecimento de um Estado imperial é interpretado por Dench como um dos demais processos em curso, no qual grupos e indivíduos foram capazes de usar e reivindicar o poder do Estado romano para vários fins. A autora questiona conceitos e instituições muitas vezes considerados preestabelecidos pela historiografia, como o de imperium no sentido de uma única entidade territorial (o "Império Romano"), que englobava províncias como unidades administrativas, compondo hotspots comunitários que concentravam a centralidade e o poder do Estado romano. Dench argumenta que, longe de serem instituições clássicas e distintas do Estado romano, conceitos como o de imperium são produtos de longos processos de formulações, modificações e transições.

Mudando o foco do conceito de imperium aplicado à esfera simbólica, Dench inicia o segundo capítulo, Territory, concentrando-se no alcance de algumas concepções, a exemplo da dominação territorial como um aspecto definidor do poder imperial do Mundo Antigo e como o alvo mais frequente da atenção do Estado diante das comunidades locais. Ao evocar as teses de Francis Haverfield (1923) e Edward Luttwak (1976) para justificar a crítica a uma historiografia que interpreta a territorialidade romana sob um ideal moderno de fronteiras racionais e estabelecidas, Dench enfatiza a complexidade dos processos de urbanização e estabelecimento de redes rodoviárias romanas.

O capítulo 3, Wealth and Society, concentra-se principalmente nas consequências econômicas do fim do modelo político republicano, bem como na relação entre a exploração econômica e o imperialismo romano. Distanciando-se de uma análise econômica cujas consequências socioculturais são abordadas com superficialidade, Dench enfatiza como as mudanças econômicas do Império afetaram o cotidiano das comunidades locais. Um exemplo disso é a análise que a autora faz sobre as regras de distribuição de cadeiras dos teatros a partir de categorias sociais estabelecida pela Lex Roscia, de 69 AEC, que se traduz como "o primeiro princípio do sistema de privilégios socialmente específicos associados ao domínio romano" (DENCH, 2018, p. 98).

Em Force and Violence, quarto capítulo do livro, Dench debruça-se sobre as questões militares e sobre os "usos performáticos e espetaculares da violência" do Estado romano. O capítulo é dedicado a explorar o papel distintivo das regras aos quais o Estado romano e 
os atores individuais estavam sujeitos. Ao mesmo tempo que enfatiza a materialidade dos atos de violência romanos, que "não eram, de forma alguma, simbólicos", Dench critica a noção de um Estado que aplicava a violência e a coerção de modo constante e irracional. Em Roma, o monopólio da violência diferia de outras potências imperiais na medida em que contava substancialmente com a força dos súditos e aliados para manter a paz dentro de suas próprias comunidades e contribuir ativamente no projeto de expansão imperial, seja pelo envio de soldados individuais ou mesmo de unidades militares.

O quinto e último capítulo, Time, analisa as concepções de passado e futuro e como estas foram moldadas pelo poder romano. Dench busca compreender como o uso de modelos de calendários e cronometragem colaboraram na configuração da relação entre o povo local e o Estado romano, "criando distâncias ou identidades entre Nós e Eles". A padronização dos sistemas de gestão de tempo romanos era, portanto, um exemplo claro de como as mudanças desencadeadas pelo Império reconfiguraram os ritmos cotidianos locais, as relações de trabalho e até mesmo os modos de conexão dos indivíduos com suas noções de passado, presente e futuro.

Dench conclui a obra argumentando que o modelo de discussão sobre as mudanças desencadeadas pelo Império Romano, dominante entre o fim do século XIX e o início do século XX, ainda não foi totalmente abandonado. Esse modelo, baseado principalmente na concepção de romanização - o "tornar-se romano" a que Dench se refere no título do epílogo - impossibilita uma apreciação dos aspectos performativos das identidades e da consciência da coexistência de grupos locais, cujos sistemas de poder estavam em contínua concorrência. Empire and political cultures in the Roman World é, portanto, o produto de novos modelos de análise das culturas políticas romanas, que consideram um império fragmentado e potencialmente mais precário, mas, ao mesmo tempo, mais flexível, resiliente e dinâmico. O mérito da obra repousa na articulação que Dench empreende entre os aspectos territoriais, simbólicos, materiais e militares de um império em constante transição. Com o amparo de uma bibliografia atualizada e um minucioso estudo da documentação primária, o livro agrega contribuições relevantes a uma historiografia interessada em questionar antigas doutrinas e reavaliar o impacto do discurso do poder romano na construção de sua própria memória.

\section{Referências}

HAVERFIELD, F. The Romanization of Roman Britain. Oxford: Clarendon Press, 1923.

LUTTWAK, E. N. The grand strategy of the Roman Empire from the first century AD to the third. Baltimore: Johns Hopkins University Press, 1976. 